\title{
O TEXTO DAS CANÇÕES INTERPRETADAS NO FILME AS CANÇÕES (2001), DE EDUARDO COUTINHO, E UM (BREVE) RETRATO DA SOCIEDADE BRASILEIRA.
}

\section{THE TEXT OF THE SONGS PERFORMED IN THE MOVIE AS CANÇÕES (2001), BY EDUARDO COUTINHO, AND A (BRIEF) PORTRAIT OF BRAZILIAN SOCIETY.}

\author{
Daniel Cristiano Santos \\ Universidade de São Paulo \\ danielcristiano@usp.br
}

\section{Resumo}

O presente artigo visa construir, a partir de breve análise das letras das canções e da montagem cinematográfica escolhidas por Eduardo Coutinho para o documentário As Canções (Brasil, 2001), um paralelo entre a representação de brasileiros e parte da literatura que aborda o tema, mais especificamente em obras de Marilena Chauí e Darcy Ribeiro. O texto é iniciado apresentando-se o contexto da utilização do gênero canção como elemento representativo da sociedade, da história do documentário e posteriormente, apresenta-se um retrato da sociedade brasileira em relação à análise de personagens da peça audiovisual propriamente dita. Como resultados da análise, é possível observar que o diretor de As Canções, se utilizou do gênero canção, em especial do texto dessas, e da escolha das obras como parte do processo de produção do filme e como forma de representação de parte da sociedade brasileira.

Palavras-chave: Canção; Cinema; Documentário; Sociedade brasileira.

\section{Abstract}

This article aims to build, from a brief analysis of the lyrics of the songs and cinematographic editing chosen by Eduardo Coutinho for 
the documentary As Canções (Brasil, 2001), a parallel between the representation of Brazilians and part of the literature that addresses the theme, more specifically in works by Marilena Chaui and Darcy Ribeiro. The text begins by presenting the context of the use of the song genre as a representative element of society, of the history of the documentary and later, it presents a portrait of Brazilian society in relation to the analysis of characters in the audiovisual piece itself. As a result of the analysis, it is possible to observe that the director of As Canções, used the song genre, especially the text of these, and the choice of works as part of the film production process and as a way of representing part of Brazilian society.

Keywords: Song; Cinema; Documentary; Brazilian society.

\section{Introdução}

presente texto visa traçar um paralelo entre personagens do longa metragem documental As Canções (Brasil, 2001), do cineasta Eduardo Coutinho, o texto das canções executadas por essas personagens e parte da literatura que aborda a formação da sociedade brasileira. A escolha deste filme se dá por meio do potencial da obra do cineasta em retratar a sociedade brasileira, principalmente no que tange os chamados excluidos e indigentes, mais especificamente neste filme onde o autor se utiliza de atores sociais (aqueles que não interpretam profissionalmente, mas a si mesmos) e canções que marcaram essas personagens, as quais têm naquele espaço, uma oportunidade de registrar, amplificar o alcance e transmitir suas histórias.

A relação entre o gênero canção e a tentativa de apresentar a personalidade e a situação dramática de uma personagem remonta a tradição do Musical, mais especificamente a canção de personagem (TRAGTENBERG, 2008). Para o autor, a canção de personagem pode "assumir o tom de protesto, desafio, testemunho, mas sempre como expressão íntima da personagem" (p. 115). Já para Grout e Palisca (2007), foi no período denominado Romantismo, especialmente na Alemanha, que a associação entre música e texto exproraria ao máximo essa possibilidade descritiva, especificamente no Lied.

Para Claudia Gorbman (2012), essa utilização de canções interpretadas por personagens, como parte integrante do universo 
diegético realista, quando o canto se situa entre música e fala, pode ser denominado como "canto amador". Nessa perspectiva a autora completa:

Eu chamo tais cenas de "canto amador", por falta de outro termo conciso para um canto que, na concepção de uma história de filme, não é um desempenho profissional, e é feito com o som sincronizado com índices adequados de um realismo espacial, sem o apoio mágico de uma orquestra. É uma organização da voz no filme que pode parecer marginal, mas pode muito bem contribuir para nossa compreensão das possibilidades da fala, música e canções no cinema (CORBMAN, 2012, p. 23)

cinema, por sua vez, tem início na Europa após o avanço na tecnologia de captura de imagens por meio da fotografia e o crescimento da utilização desta como instrumental de registro documental, pois, "documentar com uma câmera é o primeiro ato cinematográfico" (LUCENA, 2012, p. 9). Para Cousins (2013) esse primeiro contato com a recente técnica, possibilitou às pessoas, de maneira amplamente e rapidamente distribuida, a oportunidade de se submeterem a um novo tipo de imersão, pois:

De todos os primeiros filmes, os dos irmãos Lumiere foram os mais amplamente assistidos. Em 28 de dezembro de 1895, [...] eles exibiram um programa curto com seus filmes documentários para um público pagante em uma sala no Boulevard des Capucines, em Paris. Entre esses, incluía-se um filme hoje famoso em plano único chamado $A$ chegada de um trem à estação de La Ciotat (L'arrivée d'um Train Em Gare de La Ciotat, França). A câmera foi colocada perto dos trilhos, de modo que o trem aumentava gradualmente de tamanho confome se aproximava, até parecer que atravessaria a tela e invadiria a sala. As pessoas se abaixavam, gritavam ou levantavam para sair. Sentiam a emoção, como se estivessem em uma montanha-russa (COUSINS, 2013, p. 23)

Porém, mesmo com o rápido sucesso atingido pelas primeiras projeções em diversos países, o termo documentário só seria criado 
ná década de 1920, pelo crítico John Grierson!. Todavia, mesmo que o termo não seja utilizado para referir-se a todos os filmes produzidos, Nichols (2012), trabalha a ideia de que:

Todo filme é um documentário. Mesmo a mais extravagante das ficções evidencia a cultura que a produziu e reproduz a aparência das pessoas que fazem parte dela. Na verdade, poderíamos dizer que existem dois tipos de filme: (1) documentários de satisfação de desejos e (2) documentários de representação social, Cada tipo conta uma história, mas essas histórias, ou narrativas, são de espécies diferentes (NICHOLS, 2012, p. 26)

Para o autor, os documentários de satisfação de desejo são o que normalmente chamamos de ficção. São os filmes que evidenciam os desejos, sonhos, pesadelos e terrores. Tornam visíveis e audíveis os frutos da imaginação de seus criadores. Já os documentários de representação social são o que normalmente são conhecidos por "nãoficção'. O que os possibilitam são os aspectos do mundo que ocupamos e compartilhamos e a realidade social, porém, de acordo com a seleção e organização realizadas pelos produtores e/ou cineasta.

Para Lucena (2012), as denominações que discriminam os dois distintos gêneros são autoexplicativas, mas carecem de uma explanação mais aprofundada. Para o autor, em um primeiro momento, o filme documental, ou a "não-ficção" para Nichols, é visto como um ato cinematográfico que registra o mundo real, e como exemplo cita A saida da fábrica (1865) dos irmãos Lumière. Já o filme de ficção, que nasce sete anos depois, com Viagem a Lua (1902), de Méliès, é associado à construção de uma história, ao mundo da ficção.

Assim, fica clara a distinção entre os filmes de ficção e documentais e, sobre este segundo gênero, Grierson (apud LUCENA, 2012, p. 11), afirma que "cabe ao documentário (e ao documentarista)

I (1898-1972), crítico escocês que atriubuiu o nome documentário ao filme Moama (1926) de Robert Flaherty referindo-se ao termo francês documentaire que significa "coisa paralela, parecida" (Franco, 2007, p. 98). O mesmo termo era também atribuido aos chamados filmes de viagem, dessa forma, Grierson à epóca afirmou: "Moana sendo uma exposição visual dos eventos cotidianos de um jovem polinésio e sua família, tem valor como documentário" (LUCENA, 2012, p. 10). 
desenvolver esse 'tratamento criativo da realidade', mesmo que ele inclua a reconstrução de determinado acontecimento". Lucena (2012) expressa também esse aspecto de reconstrução da realidade intrínseco aos documentários, e cita como exemplo o filme Nanook (1926), também de Robert Flaherty, onde após a morte do ator principal, o cineasta contratou um ator japonês para representar um nativo do Alasca em algumas cenas, teria utilizado também, arpões que não eram conhecidos pelos nativos em 1922, construiu um iglu muito maior que o comum para que a câmera pudesse ser manuseada em filmagens em seu interior e teria desenvolvido vestimentas para os atores. Reinventando assim "uma realidade da qual, no momento da filmagem, muitos elementos teriam sido, na melhor das hipóteses, ultrapassados ou, na pior, inexistentes" (CUERRIN e MANDELBAUN, 2006, p. 3).

Para além disso, Nichols (2012) afirma:

Como histórias que são, ambos os tipos de filme pedem que os interpretemos. Como "histórias verdadeiras" que são, pedem que acreditemos neles. A interpretação é uma questão de compreender como a forma ou organização do filme transmite significados e valores. A crença depende de como reagimos a esses significados e valores. Podemos acreditar nas verdades das ficções, assim como nas das não ficções [...] a crença é encorajada nos documentários, já que eles frequentemente visam exercer um impacto no mundo histórico e, para isso, precisam nos persuadir ou convencer de que um ponto de vista ou enfoque é preferivel a outros. [...] Do documentário não tiramos apenas prazer, mas uma direção também (NICHOLS, 2012, p. 27)

Do ponto de vista descritivo e de representação da realizade, assim como o genêro canção, o documentário possibilita "representações auditivas e visuais de uma parte do mundo histórico" e que "o aspecto da representação é fundamental para o documentário" (NICHOLS, 2012, p. 30). 


\section{As Canções}

Eduardo de Oliveira Coutinho, cineasta paulistano (19332014), tem uma cinematografia "marcada pela entrevista como forma dramática praticamente exclusiva" (XAVIER, 20 10, p. 66), sendo que em seu filme As Canções (200 I), esse elemento esteve presente de maneira central. Para Frochtengarten (2007), a marca essencial de Coutinho são "as entrevistas que realiza com pessoas anônimas. Seus documentários são compostos por uma sucessão de entrevistas após as quais caem os letreiros. Nada mais (FROCHTERCARTEN, 2009, p. 125).

A escolha dessa, que é sua $12^{\circ}$ obra, se deu por conta da formação do pesquisador, pelo interesse contínuo em análises sobre o assunto e pela utilização do gênero canção em sua possibilidade de representação, reunindo a arte, a história e a política no processo de análise da obra que é vencedora do Festival do Rio 2011. Para sua realização, Eduardo Coutinho se fez valer de anúncios em jornal e na internet, convidando pessoas comuns do Rio de Janeiro a contarem suas histórias por meio de canções com as quais se identificassem. Além disso, pesquisadores foram às ruas de diversos pontos da cidade do Rio de Janeiro carregando cartazes onde estava escrito "Alguma música já marcou sua vida? Cante e conte sua história". Ao final, 237 pessoas foram selecionadas e 45 delas foram efetivamente filmadas, sendo que na versão final do filme é possível observar a presença de cerca de 17 entrevistados, com idades entre 22 e 82 anos.

O filme apresenta formato ensaístico, de prática confessional e de autoficção, que "são escolhas e procedimentos estéticos empregados em um número crescente de filmes brasileiros, sobretudo aqueles tomados por documentais" (MARZOCHI, 2012, p. 21), dessa forma, Eduardo coutinho se fez valer dessas possibilidades em As Canções assim como já havia feito em Jogo de cena (2007), ou ainda, João Moreira Salles havia utilizado em Santiago (2007) como bem lembra a autora. Em complemento, Xavier (apud MARZOCHI, 2012, p. 21), afirma que "a noção de filme ensaio abriria um novo caminho para repensar as articulações entre o que a tradição chama de ficção e de documentário", aproximando assim ambos os gêneros novamente, como fora na criação do termo documentário, por John Grierson. 
Essa conjunção entre ficção e documentário (entendido enquanto algo relacionado a verdade, mesmo que não absoluta), e os motivos para o tipo de filmagem (câmera parada, interlocutor em primeiro plano, fundo simples) que o cineasta utiliza, ficam bem explícitos na fala do próprio Coutinho quando entrevistado por Frochetengarten (2009) e questionado sobre sua preferência ao termo 'conversa' no lugar de 'entrevistas':

Se há uma coisa que acho que aprendi, por razões obscuras, é conversar com os outros. Com Câmera, porque sem câmera eu não falo com ninguém.

A maioria dos que fazem documentário fazem, efetivamente, entrevistas. As entrevistas têm um lado jornalístico e de depoimento. Entrevistas e depoimentos são coisas para a História. São coisas que se fazem com especialistas. E eu trabalho com pessas comuns. A pessoa conta um fato histórico e, se ele é verdadeiro ou não, deixa de ter importância [...]. Eu não me interesso em filmar os objetos, a casa da pessoa, em detalhar a condição social. $O$ que me interessa é um rosto que fala. Existem filmes em que, para cortar, mostram um cachorro no chão, um quadro na parede. Nos meus filmes, não. As pessoas falam com o verbal e com o gestual [...]. Tem filmes em que a pessoa diz 'Eu trabalho em um banco' e então ele aparece trabalhando. Você vai provar o quê Que aquilo é real? Isso é absolutamente banal, totalmente inútil. Se borrar essa imagem, ela vira um conceito que aprisiona. As filigramas do discurso é que são o real. Então eu tenho que ter uma grande fé na possiblidade da palavra (FROCHETENCARTEN, 2009, p. 128-130)

filme se inicia com a personagem Sonia Regina do Nascimento cantando um trecho de "Minha Namorada" de Carlos Lyra e Vinícius de Moraes, que serve não somente como tema de abertura de um filme que se utiliza de conversas enquanto meio de condução, por seus versos: "E também de não perder esse jeitinho / De falar devagarinho / Essas histórias de você", mas também por sua continuação: "Aquela amada pelo amor predestinada / Sem a qual a vida é nada / Sem a qual se quer morrer / Você tem que vir comigo em meu caminho / E talvez o meu caminho / Seja triste pra você", demonstrando aqui a questão da serviciência da mulher, em um contexto misógeno, onde, mesmo que o "caminho seja triste para você" a mulher foi predestinada ao "seu" 
homem, não valendo-se aí da liberdade que the é facultativa pelo estado de direito. Chauí (200l) aborda a essa mesma ideia, todavia relacionada ao povo nativo quando da chegada nos navegantes $e$ colonizadores, sobre isso, explica:

\begin{abstract}
[...] os índios, dizem os navegantes e os colonizadores, são gente "sem fé, sem lei e sem rei". Nessas condições, estão naturalmente subordinados e sob o poder do conquistador. Todavia, se essa teoria parecer excessivamente brutal, pode-se corrigi-la com o conceito de servidão voluntária. [...] A escolha significa que a vontade é uma capacidade e que seu exercício depende da racionalidade do sujeiro de direito. Uma capacidade é uma faculdade e é da essência de uma faculdade poder exercer-se ou não ser exercidade, isto é, seu uso é facultativo (CHAUÍ, 2001, p. 66)
\end{abstract}

Esse entendimento do sentido "natural" de que o índio não é "afeito a lavoura" mas o negro sim estará no cerne da proposta escravista no país, que entendia que essa "afeição natural" no processo de naturalização da escravidão no país estaria atrelada ao tráfico negreiro que "abria um novo e importante setor do comércio colonial" (CHAUI, 2001, p. 67).

É sabido que a escravidão termina no Brasil mas que os negros não deixam de ser subjulgados em muitos setores da sociedade, para Darcy Ribero em seu livro $\bigcirc$ Povo Brasileiro, quando os negros passam a povoar as cidades, tem de aprender modos de vida da cidade, e nessa imersão integrativa com os negros que já teriam se instalado ali anteriormente e que "já haviam construído uma cultura própria, na qual se expressavam com alto grau de criatividade. Uma cultura feita de retalhos do que o africano guardara [...], como sentimentos musicais, ritmos, sabores e religiosidade' e complementa: "A partir dessas precárias bases, o negro urbano veio a ser o que há de mais vigoroso e belo na cultura popular brasileira" (RIBEIRO, 1995, p. 222).

Tendo em vista esta perspectiva, é possivel voltar para As Canções e verificar que a segunda personagem apresentada por Coutinho, Déa Franco, nome artístico para Justina Maria Franca Wandschneider, uma mulher de 82 anos, negra, trabalhou como cantora na era dos Festivais das décadas de 1950 e 1960, que traz em sua fala: 
A minha tia dizia... eu acho que eu nasci cantando, sabe porquê? Porque a minha tia, uma das minhas tias disse assim: - Que quando eu era criança, eu vivia berrando dentro de casa, cantando aquela música ' $O$ seu cabelo não nega, mulata'. Aí começaram a dizer assim: Porque você não vai cantar no programa do Ary Barroso? $\bigcirc$ primeiro programa que cantei na minha vida foi do Ary Barroso

\section{Para Ribeiro ( 1995):}

Com base nela é que se estrutura o nosso Carnaval, o culto de lemanjá, a capoeira e inumeráveis manifestações culturais. Mas o negro aproveita cada oportunidade que the é dada para expressar o seu valor. Isso ocorre em todos os campos em que não se exige escolaridade. É o caso da música popular, do futebol e de numerosas formas menos visíveis de competição e de expressão. $\bigcirc$ negro vem a ser, por isso, apesar de todas as vicissitudes que enfrenta, o componente mais criativo da cultura brasileira e aquele que, junto com os índios, mais singulariza o nosso povo (RI$\mathrm{BEIRO}, 1995$, p. 223)

A base a qual o autor cita na passagem está relacionada a cultura dos negros que puderam, após o fim da escravidão, ser expressa nos mais diferentes âmbitos da sociedade, mas que, não garantiu a população negra o acesso a todas as premissas sociais de igualdade e distribuição de renda, Chauí (2001) afirma que:

Brasil ocupa o terceiro lugar mundial em índice de desemprego [...], ocupa o segunda lugar mundial nos índices de concentração da renda e de má distribuição da riqueza, mas ocupa o oitavo lugar mundial em termos do Produto Interno Bruto. A desigualdade na distribuição da renda - 2\% possuem 98\% da renda nacional, enquanto 98\% possuem 2\% dessa renda - não é percebida como forma dissimulada de apartheid social ou como socialmente inaceitável, mas é considerada natural e normal [...]. em outras palavras, a sociedade brasileira está polarizada entre a carência absoluta das camadas populares e o privilégio absoluto das camadas dominantes e dirigentes (CHAUI, 2001, p. 97) 
E mesmo que o país à época da produção do filme vivenciasse um clima de otimismo por conta dos liberalismo econômico vivenciado nos governos FHC e Lula (CASTELO, 2012, p. 613) esses negros ainda são levados a viver muitas vezes em comunidades carentes, imersos a violência provocadas pela ausência do Estado nessas comunidades, este é o caso de outro personagem do filme, Queimado, alcunha de Gilson José dos Santos Santana, que além de gostar muito de música, como o próprio afirma:

\begin{abstract}
[...] Porque se você presta atenção, o cara que vive numa comunidade carente, como eu vivo, eu moro no pé do Morro do Chapadão. Vocês de...Esses dias vocês deve ter ouvido falar, de vez em quando tem um defuntinho pra lá, um defuntinho pra cá, né? Uma bala perdida pra lá.... Ultimamente eu só saio pra trabalha depois que eles dão tiro, porque já me acostumei, se não der tiro, não saio...
\end{abstract}

A personagem demonstra também a característica religiosa, como observou Ribeiro (1995) anteriormente e seu depoimento explicita essa religiosidade no trecho a seguir:

[...] Tudo o que tô fazendo aqui, eu queria que tú... eu queria te pedi um favor... Tudo bem que tá gravano aí. Eu queria que você... Independente do que vai ao ar, é que só que tú exaltasse uma coisa que eu preciso que você faça pra mim, por favor. É que tudo que eu tô fazendo aqui é pra honra e glória do Nosso Senhor Jesus Cristo...Sem Jesus eu não sou nada... Eu não me emociono falando de Jacira, mas de Jesus eu me emociono, porque ele é o melhor que tem em mim. Moreno ???, moro em favela, tenho 6 filhos, já fui ladrão, já roubei. Hoje em dia sou um homem de bem repeitado pelos meus filhos e pelas pessoa que me rodeia.. Minha palavra parece lei onde eu moro e no meu trabalho. Só uma pessoa foi capaz de me reconhecer e me ver como gente, foi meu Deus

Outro conceito importante que pode ser observado no filme é a presença do "Homem Cordial", aquele movido pelo cor, o coração, as emoções, como explica Sérgio Buarque de Holanda (apud CHAUÍ, 2001 ): 
Já se disse, numa expressão feliz, que a contribuição brasileira para a civilização será de cordialidade [...] a lhaneza no trato, a hospitalidade, a generosidade, virtudes tão gabadas por estrangeiros que nos visitam, representam com efeito, um traço definido do caráter brasileiro, na medida, ao menos, em que permance ativa e fecunda a influência ancestral dos padrões de convivio humano, informados no meio rural e patriarcal. Seria engano supor que essas virtudes possam significar "boas maneiras", civilidade. São antes de tudo expressões legítimas de um fundo emotivo extremamente rico e transbordante (CHAUÍ, 2001, p. 97)

Essas mesmas emoções, à flor da pele, são demonstradas pela personagem Lidia Silva Montezuma, que após contar sobre seu romance com um homem casado, no qual teve uma filha, explica:

Nessa ocasião também, esqueci de falar isso, comprei um revólver, depois desse dia que ele me deixou lá, me recomendando pra ir pra casa pra não pegar gripe. Isso aí era meia noite, uma hora da madrugada, e eu morava lá na vila Rosali, e estava na Pavuna, andava aquilo tudo ali. Eu comprei um revólver e um dia tomei um porre e fui lá pra dá um tiro nele, aí eu falei: "- Vou entrar nesse carro não", ele falou: "- Vai"... jeito que eu estava transtornada... e entrei no carro, e ele acelerou... "- Vou te deixar em casa e vou embora pra casa que eu tenho compromisso", eu falei assim: "- Seu compromisso hoje vai ser no céu", ele falou: "- Porquê?", eu falei: "Porque você vai morre"... mas, pela misericórdia desse Deus que eu odiava, a bala não saiu. Eu aperte, uma, duas, ele deu uma guinada com o carro....[pausa] e parou. Tentou tirar mas, eu era muito forte, tava com muito ódio... e eu saltei e fui a pé, num quis ir junto, recusei o carro dele. Acho que foi a primeira vez que eu tomei uma atitude de caráter... "- Num vou no seu carro, não. Hoje quem vai a pé, sou eu [...]

Após esse momento, quando indagada por Coutinho se aqueles momentos foram bons ou ruins, Lidia Silva diz que foram bons $e_{\text {, saindo }}$ de cena, chora copiosamente. 
A questão da religiosidade e do movimento protestante também são apresentadas na obra de Coutinho, onde nessa obra traz a presença da personagem Gilmar, um homem que frequentava a lgreja Batista tradicional e que asssume que a música e sua falecida esposa é que o mantinham frequentando a denominação. A presença do "homem do campo", filho de lavradora, de estrangeiros e da valorização da cultura popular brasileira também estão presentes, mais especificamente na presença das personagemns Ózio e Isabell, respectivamente. Esta última afirma:

Eu morava em Londres... eu comecei capoeira em Londres e todo bom capoeirista tem que ir pro Brasil, ao menos uma vez, para saber como é jogado aqui [...] Eu cheguei, eu viajei, achei um grupo interessante aqui no Leme, de Capoeira Angola, comecei a praticar lá e foi a láqui que conheci meu marido[...]

Já para Ózio, o motivo de seu êxodo para a cidade foi a perda da mãe, esposa e sogra:

Foi o que me jogou fora do interior foi a falta deles [...] perdi três mães seguidas.

Essa mesma personagem, de forma intuitiva, compôs uma canção como forma de se despedir de sua esposa:

Vai simbora, meu bem, vai simbora / Me acompanha da lua ao clarão / Vai deixando a tua saudade / colocada no meu coração. Nesta noite sonhei, que nunca mais eu te vi / mas quando eu acordei, tantas amarguras eu passei / quero te ver bem distante, pra nunca mais ouvir, deve partir o quanto antes, Oh mulher! Para acabar meu sofrer / Soltei o pio no mato, o inhambu não me arrespondeu, não tem ninguém neste mundo, Oh Mulher! Que sofra mais do que eu (sic) 
Múltiplos outros olhares são possiveis sobre a obra de Eduardo Coutinho, bem como a utilização do gênero canção no cinema documentário, e esse texto não pretende, de nenhuma maneira, esgotar nem mesmo a abordagem aqui apresentada. E mesmo que o gênero documental, desmitificado da questão da verdade absoluta, possibilite o contato do espectador ao menos com o ponto de vista do cineasta, Frochtengarten (2009) relembra que:

As histórias dessas pessoas nos chegam através de entrevistas feitas pelo próprio cineasta que, acompanhado de sua equipe, aparece nas imagens. A explicitação do método pelo diretor-personagem insiste em lembrar que - cinema é transformador da realidade retratada, E que - filme que ora assistimos é uma representação do real (FROCHTENGARTEN, 2009, p. 126).

Essa representação do real, aqui tratada também como representação da sociedade brasileira é um tema possível para aprofundamentos futuros, considerando a possibilidade quase inesgotável de olhares possíveis sobre a obra cinematográfica. 


\section{Considerações}

Observando o filme As Canções e tendo em vista o texto das canções escolhidas e interpretadas pelas personagens do filme, posteriormente escolhidas e editadas pelo cineasta no processo de montagem do filme, observou-se a possibilidade de relacionar tais escolhas a obras que buscam retratar a sociedade brasileira, em algumas de suas facetas.

A herança escravocrata, a figura do "homem cordial", a presença da miscigenação, as diferentes entidades e denominações cristãs, retratam a pluralidade e contrastes da sociedade brasileira.

Do ponto de vista técnico musical, a obra de Coutinho apresenta, em diversos momentos, a utilização do "canto amador", aqui entendido na perspectiva de Claudia Corbman, como sendo aquele se situa na fronteira entre o gênero musical e a fala. Tal forma de canto, para a proposta apresentada pelo documentário, funciona como o catalisador das memórias dos entrevistados que, ao exporem as canções escolhidas, contam também sua própria história.

\section{Bibliografia}

CASTELO, R. "O novo desenvolvimentismo e a decadência ideológica do pensamento econômico brasileiro". In: Serviço Social E Sociedade, n. 112, p. 613-636. São Paulo : s.n., 2012.

CHAUÍ, M. Brasil: Mito fundador e sociedade autoritaria. São Paulo : Perseu Abramo, 2001.

COUSINS, M. História do Cinema: dos clássicos mudos ao cinema moderno. Trad. Cecilia Camargo Bartalotti. São Paulo : Martins Fontes Selo Martins, 2013.

FRANCO, M. "Cinedocumentário: refistro de memórias, inventário de culturas" in: Memória e cultura: A importância da memória na formação cultural humana. Org: Danilo Santos Miranda. São Paulo : SESC SP, 2007. 
FROCHTENGARTEN, F. "A entrevista como método: uma conversa com Eduardo Coutinho". In: Psicologia USP, 20 ( 1), 125-138. São Paulo : USP, 2009.

CORBMAN, C. "O canto amador". Trad. José Claáudio S. Castanheira. In: SÁ, Simone Pereira de; COSTA, Fernando Morais (org.). Som + Imagem. Rio de Janeiro : 7 letras, 2012.

GROUT, D. J. \& PALISCA, C. V. Historia da Música Ocidental. [trad.] Ana Luísa Faria. s.I. : Gradiva, 2007. Vol. $5^{\circ}$ Volume.

CUERRIN, M e MANDELBAUN, J. Os Infernos de Darwin. Folha de São Paulo, Mais!, 2 de abril de 2006. São Paulo : s.n., 2006.

LUCENA, L. C. Como fazer documentários: conceito, linguagem e prática de produção. São Paulo : Summus, 2012.

MARZOCHI, I. F. Jogos de cena: Ensaios sobre o documentario brasileiro contemporâneo. [Tese de doutorado]. São Paulo : Programa de Pós-graduação em Ciências da Comunicação da Escola de Comunicações e Artes da Universidade de São Paulo, 2012.

NICHOLS, B. Introdução ao documentário. Trad. Mônica Saddy. Campinas-SP : Papirus, 2012.

RIBEIRO, D. O Povo Brasileiro: A formação e o sentido do Brasil $2^{a}$ edição. São Paulo : Companhia das Letras - 1995, 1995.

TRAGtenberG, L. Música de Cena. São Paulo : Perspectiva, 2008.

XAVIER, I. "Indagações em torno de Eduardo Coutinho e seu diálogo com a tradição moderna". In: MICLIORIN, C. (org.). Ensaios no real: o documentário brasileiro hoje. Rio de Janeiro : Azougue, 2010.

\section{Filmografia}

CANÇÕES, As. Direção de Eduardo Coutinho. Brasil, 201 1. (92 min): son. Color 


\section{Sobre o autor}

Daniel Cristiano Santos, Mestre em Desenvolvimento Humano pela Universidade de Taubaté (UNITAU), doutorando em Música pela USPSP sob a orientação do Prof. Dr. Amilcar Zani. Iniciou os estudos de piano aos sete anos de idade passando pelos professores: Maria Valéria F. Leite, Fábio Ferreira, Donata M. Lange (Polônia) e Mauricy Martin (Unicamp-SP), foi aluno de música de câmara de George Kiszely (Hungria) e Fernando Tomimura (Fundação Osesp e Escola Municipal de Música de São Paulo), realizou ainda masterclasses com Richard Bishop (Julliard School), Saraí Sarmiento (Cuba), Sérgio Gallo (Ceorgia State University-USA), entre outros. Integrante do Quinteto de Cordas da cidade de Taubaté (2009-2019) e professor na Escola Municipal de Artes "Maestro Fêgo Camargo" desde 2009. Com uma produção diversa nos campos da música de concerto, produção acadêmica e audiovisual, atua como pianista no Ópera Stúdio do Vale. Desde 2016 pesquisa e grava a obra de Yves Rudner Schmidt.

Recebido em 29/07/2019

Aprovado em 02/04/2020 